\title{
Vaginal Colonization by Escherichia coli in Pregnant Women at King Abdulaziz University Hospital, Jeddah, Saudi Arabia
}

\author{
Taghreed Y. Jamal', MSc, Hassan El-Banna A. Younus², MD, \\ Hassan S. Abduljabbar ${ }^{3}$, FRCS(C), Asif A. Jiman-Fatani ${ }^{4}$, PhD, \\ and Amal F. Makled ${ }^{2}$, MD
}

'Department of Biology, Faculty of Science, King Abdulaziz University, Jeddah, Saudi Arabia

${ }^{2}$ Department of Microbiology and Immunology, Faculty of Medicine, Menoufiya University

Menoufiya, Egypt

${ }^{3}$ Department of Obstetrics and Gynecology, Faculty of Medicine, King Abdulaziz University, Jeddah, Saudi Arabia

${ }^{4}$ Department of Medical Microbiology and Parasitology, Faculty of Medicine, and Clinical and Molecular Microbiology Laboratories, University Hospital, King Abdulaziz University, Jeddah, Saudi Arabia

\section{Correspondence \\ Ms. Taghreed Y. Jamal \\ P.O. Box 36161 \\ Jeddah 21419, Saudi Arabia \\ e.M:Tyjamal@kau.edu.sa \\ Submission: 23 April 2017 \\ Accepted: $\quad 28$ May 2017}

\section{Citation}

Jamal TY, Younus HA, Abduljabbar HS, Fatani AA Makled AF. Vaginal colonization by Escherichia coli in pregnant women at King Abdulaziz University Hospital, Jeddah, Saudi Arabia. JKAU Med Sci 2017; 24 (3): 39-49. DOl: 10.4197/Med. 24.3.4

\begin{abstract}
Maternal and neonatal infections by Escherichia coli remain a challenging problem for obstetricians and pediatricians. This study aims to determine the prevalence of vaginal colonization by Escherichia coli among pregnant women attending the Antenatal Clinics at King Abdulaziz University Hospital in Jeddah- Saudi Arabia, and to investigate the susceptibility of isolated Escherichia coli to the most commonly used antimicrobials. In this study, 100 pregnant women in the last trimester and 25 non-pregnant women were screened for vaginal colonization of Escherichia coli. The suspected colonies were identified by conventional methods and were confirmed by automated technology "Vitek 2 System". Also, antimicrobial susceptibility tests were done by the same methods". Escherichia coli isolates were serotyped to detect the presence of K1 antigen. Out of 100 pregnant women in the last trimester; twenty-one (21\%) were Escherichia coli positive. Also, out of 25 non-pregnant women; four (16\%) were Escherichia coli-positive. All of the isolated Escherichia coli were susceptible to most antimicrobial agents. The percentage of vaginal Escherichia coli resistance to trimethoprim/sulfamethoxazole, ampicillin and piperacillin ranged from $38.1 \%$ to $42.9 \%$. The virulence factor $\mathrm{K} 1$ antigen was demonstrated in $42.9 \%$ of Escherichia coli -positive pregnant women.
\end{abstract}

Keywords

Escherichia coli K1 strains; Vaginal colonization; Pregnant women;

Saudi Arabia 


\section{Introduction}

E scherichia coli (E. coli) and group B streptococcus are the most common causative pathogens of neonatal sepsis and meningitis which result in neonatal morbidity and mortality ${ }^{[1,2]}$. Escherichia coli is a common vaginal microflora of pregnant and nonpregnant women and has been identified as a vaginal colonizer in $24-31 \%$ of pregnant and $9-28 \%$ in nonpregnant women ${ }^{[3]}$. Previous studies explained that the high prevalence of $E$. coli in vaginal colonization is due to the proximity of the vagina to anus, the large numbers of $E$. coli constantly shed in the female's own fecal flora and due to the functional changes that occur in pregnant females ${ }^{[4,5]}$. Escherichia coli strains involved in neonatal infections originate from the vagina, which is colonized by the rectal source ${ }^{[6]}$. Vaginal colonization by $E$. coli can cause ascending infections, usually after rupture of membranes, leading to preterm birth and other maternal and fetal morbidities ${ }^{[3,7]}$. Many complications of $E$. coli infections can occur such as urinary tract infections, low birth weight neonates, early-onset neonatal sepsis and meningitis ${ }^{[3,7]}$. According to the "National Neonatal Perinatal Data (NNPD) 2002-2003", the incidence of neonatal sepsis that caused by different microorganisms is $30 / 1000$ live births ${ }^{[8]}$. Some reports in Libya, Egypt, Jordan, and Iraq demonstrated that $E$. coli and other gram negative organisms were the causative pathogens in 65\%-90\% of all neonatal sepsis cases ${ }^{[9]}$. Bassuni et al. ${ }^{[10]}$ found that E. coli is the predominant organism causing neonatal sepsis in the Asir region of Saudi Arabia. Escherichia coli vaginal colonization in pregnant women was found to be $10.8 \%$ in Nigeria and 15\% in Spain; while it was found to be $13.7 \%$ in Pakistan, $9.2 \%$ in Nigeria and in $12 \%$ in Spain in non-pregnant women ${ }^{[11-13]}$. The neonates acquire $E$. coli infections from the maternal birth canal before or during delivery leading to earlyonset neonatal septicemia within the first week of life $^{[1,14]}$.

Approximately $80 \%$ of the cases of E. coli neonatal meningitis are caused by strains possessing K1 capsular polysaccharide ${ }^{[15]}$. Some studies identified antimicrobial resistant vaginal $E$. coli strains in pregnant women; $85 \%$ of them were resistant to at least one drug, $30 \%$ were multi-drug resistant, $42.5 \%$ were extended spectrum beta-lactamase-producers. So, detection and proper management for these resistant strains during pregnancy can reduce the morbidity and mortality in neonates ${ }^{[16]}$.
This study aims to determine the prevalence of E. coli vaginal colonization among pregnant women attending the Antenatal Clinics at King Abdulaziz University Hospital (KAUH), to compare E. coli colonization in these pregnant and non-pregnant women and to investigate the susceptibility of isolated E. coli strains to the most commonly used antimicrobial agents.

\section{Materials and Methods}

This study was planned and designed as a casecontrol study and was carried out during the period from September 2012 to September 2013 at KAUH in Jeddah, Saudi Arabia. High vaginal swabs (HVSs) were collected from 100 pregnant women during the last trimester of the pregnancy (Group 1) and from 25 non-pregnant women (Group 2). Age of these women ranged from 18 to 45 years who attended the outpatient clinics of the Department of Obstetrics and Gynecology. Questionnaires regarding full history of these women were filled out. The collected vaginal swabs were transported to the Clinical and Molecular Microbiology Laboratory (at KAUH) in Stuart's transport media "(Nouva Aptaca S.r.l., Canelli, Italy)" immediately. These swabs were cultured on MacConkey's agar plates "(Saudi Prepared Media Laboratory Ltd. Co., Jeddah, Saudi Arabia)" and incubated for 24-48 hours at $37^{\circ} \mathrm{C}$ aerobically. The suspected E. coli colonies were identified by conventional methods ${ }^{[17]}$ including; colony appearance, Gram staining and series of standard bacteriological tests ${ }^{[18]}$. "Vitek 2 (bioMérieux Inc., St. Louis, MO, USA)" was used for confirmation of the $E$. coli isolates colorimetrically. Also, antimicrobial susceptibility testing was done by "Vitek 2 using ampicillin, amoxicillin/clavulanic acid, piperacillin, piperacillin/tazobactam, cefuroxime, cefotaxime, cefepime, meropenem, amikacin, gentamicin, ciprofloxacin, nitrofurantoin and trimethoprim/ sulfamethoxazole as per Clinical Laboratory Standard Institute (CLSI) Standards and Guidelines" (CLSI., Wayne, PA USA). The E. coli isolates were serotyped by utilizing "BD Directigen ${ }^{\mathrm{TM}}$ Meningitis Latex Test System (Becton, Dickinson and Co., Franklin Lakes, NJ USA)" which is a presumptive" latex agglutination test" to detect K1 capsular polysaccharide antigen in the isolates.

This study was approved by the Research Ethics Committee of the Faculty of Medicine, King Abdulaziz University (Reference Number: 823-12). Data were collected, tabulated and statistically analyzed using SPSS for Windows, version 16 (SPSS Inc., Chicago, IL 
USA). Significance was made using chi-square test for non-parametric parameters and "student's" $t$ test for parametric parameters.

\section{Results}

Out of 100 pregnant and 25 non-pregnant women; $21 \%$ and $16 \%$ were positive for E. coli vaginal colonization respectively with significant difference between them. The demographic and clinical data of pregnant and nonpregnant women are shown in Table 1 where the mean age of pregnant and non-pregnant women was $30.73 \pm$ 5.93 and $32.36 \pm 6.40$, respectively without significance difference $(P=0.229)$. There was a significant difference between pregnant and non-pregnant in both Saudi and non-Saudi women $(P=0.0001)$. All pregnant and non-pregnant women in this study were from urban areas. The most common co-morbidity was urinary tract infections in pregnant women (18\%) and in nonpregnant women (16\%). Further detailed analysis of the clinical data with the significance shown on Table 1

The most common co-morbidity in E. coli-positive and E. coli-negative pregnant women was urinary tract infections during the current study $(28.6 \%$ and $15.2 \%$, respectively) as shown in Figure 1 but without significant difference $(P=0.137)$. The other comorbidities such as diabetes mellitus and hypertension were higher in E. coli-positive than E. coli-negative pregnant women (Fig. 1). Further comparative analysis and significance shown on Table 2

The history of previous premature rupture of membranes (PROM) in pregnant women was $4.8 \%$ in E. coli-positive and $1.3 \%$ in E. coli-negative with no significant difference $(P=0.378)$ as shown in Figure 2 . The history of previous neonatal deaths were $23.8 \%$ in E. coli-positive and $5.1 \%$ in E. coli negative pregnant women with significant difference $(P=0.019)$ as shown in Figure 3.

Table 3 shows the antimicrobial susceptibility patterns of the isolated E. coli strains in pregnant women. It was found that all E. coli isolates $(100 \%)$ were susceptible to "amoxicillin- clavulanate, piperacillintazobactam, cefuroxime, cefotaxime, cefepime, meropenem, amikacin, gentamicin, ciprofloxacin and nitrofurantoin". Meanwhile, 12 (57.1\%) of E. coli isolates were sensitive to ampicillin and piperacillin. Thirteen $(61 \%)$ of the isolates were sensitive to trimethoprim। sulfamethoxazole.
Figure 4 shows the results of screening for serotype E. coli $\mathrm{K} 1$ in pregnant women. The percentage of E. coli $\mathrm{K} 1$ strains in pregnant women was $42.9 \%$. There was insignificant difference in pregnant and non-pregnant women regarding $\mathrm{K} 1$-positivity $(P=0.083)$. Further detailed analysis and significance on pregnant and nonpregnant shown on Table 4.

\section{Discussion}

Escherichia coli is one of the most common enteric microorganisms which is found frequently in the female genital tract ${ }^{[12]}$. This microorganism possesses several virulence factors that allow it to cause vaginal colonization and has been implicated in different infections in pregnant women, mostly in urinary tract infections ${ }^{[12]}$. Maternal and neonatal infections caused by $E$. coli remain a challenging problem for obstetricians and pediatricians because of the risk of early onset neonatal sepsis and meningitis caused by this organism which is obtained from the mother's birth canal before or during delivery ${ }^{[14]}$. Therefore, it is useful to screen pregnant women for genital tract colonization by $E$. coli during the prenatal period ${ }^{[19]}$.

In this study, out of 100 pregnant women and 25 non-pregnant women (control group); 21 (21\%) and $4(16 \%)$ were $E$. coli-positive, respectively with significant difference between them $(P=0.001)$. Higher results of vaginal colonization by $E$. coli in pregnant women were recorded by Al-Mayahie ${ }^{[20]}$ in Iraq and August ${ }^{[21]}$ in Tanzania (37.7\% and 30\%, respectively). Moreover, similar results of vaginal colonization by E. coli in pregnant women (19.9\%) were reported by Barcaite et al., ${ }^{[22]}$ in Lithuania. On the other hand, lower results were found by Al-Inany et al., ${ }^{[23]}$ in Egypt (17\%), Devi et al., ${ }^{[16]}$ in India (16.2\%), Hamedi et al., ${ }^{[24]}$ in Iran (15\%), Guiral et al., ${ }^{[12]}$ in Barcelona, Spain (15\%), Villar et al., ${ }^{[6]}$ in Argentina (14.3\%), Akerele et al., ${ }^{[25]}$ in Nigeria (13.5\%), Basu et al. ${ }^{[8]}$ in India (11.2\%), Zaria et al., ${ }^{[11]}$ in Nigeria (10.8\%), Agbakoba et al., ${ }^{[26]}$ in Nigeria (8.3\%) and Ghartey et al., ${ }^{[27]}$ in USA (10\%). However, the lowest results were found in some studies that were done by Budisan and $\| l i e^{[28]}$ in Romania (5.9\%) and by ObataYasuoka et al., ${ }^{[3]}$ in Japan (3.4\%) and by Wong ${ }^{[29]}$ in Hong Kong (2.4\%). Rates of $E$. coli colonization in vagina may vary greatly according to the sample source, the culture medium used, the ethnic group, geographical location, socioeconomic status, immunological factors and the age of the population investigated ${ }^{[30]}$. 
Vaginal Colonization by Escherichia coli in Pregnant Women at King Abdulaziz University Hospital, Jeddah, Saudi Arabia T.Y. Jamal et al.

Table 1. Demographic and clinical data of all participants (pregnant and non-pregnant women).

\begin{tabular}{|c|c|c|c|}
\hline Parameters & $\begin{array}{l}\text { Pregnant } \\
(\text { No. }=100)\end{array}$ & $\begin{array}{c}\text { Non-Pregnant } \\
\left(\text { NNo. }_{2}=25\right)\end{array}$ & $\begin{array}{c}\text { Significance } \\
(P . \text { value })\end{array}$ \\
\hline Age (Years) & $30.73 \pm 5.93(18.00-42.00)$ & $32.36 \pm 6.40(23.00-45.00)$ & 0.229 \\
\hline Nationality & & & 0.283 \\
\hline Saudi & $48(48.00 \%)$ & $15(60 \%)$ & 0.0001 \\
\hline Non-Saudi & $52(52 \%)$ & $10(40 \%)$ & 0.0001 \\
\hline \multicolumn{4}{|l|}{ Residency } \\
\hline Urban & $100(100 \%)$ & $25(100 \%)$ & 1.000 \\
\hline Rural & 0 & 0 & - \\
\hline \multicolumn{4}{|l|}{ Co-Morbidity } \\
\hline Diabetes mellitus & $7(7 \%)$ & - & - \\
\hline Urinary Tract Infections & $18(18 \%)$ & $4(16 \%)$ & 0.814 \\
\hline Smoking & $1(1 \%)$ & $2(8 \%)$ & 0.041 \\
\hline Hypertension & $7(7 \%)$ & - & - \\
\hline Previous Pre-eclampsia & $2(2 \%)$ & $1(4 \%)$ & 0.559 \\
\hline Cancer & $1(1 \%)$ & $1(4 \%)$ & 0.285 \\
\hline Immunodeficiency & $2(2 \%)$ & $1(4 \%)$ & 0.559 \\
\hline Contraceptive uses & $79(79 \%)$ & $13(52 \%)$ & 0.048 \\
\hline Loop & $10(10 \%)$ & $2(8 \%)$ & 0.021 \\
\hline Pills & $29(29 \%)$ & $6(24 \%)$ & 0.0001 \\
\hline Others (Condoms) & $40(40 \%)$ & $6(24 \%)$ & 0.0001 \\
\hline Antibiotics Usage & $13(13 \%)$ & $4(16 \%)$ & 0.696 \\
\hline \multicolumn{4}{|l|}{ Types of Antibiotic } \\
\hline Amoxicillin/Clavulanate & $11(11 \%)$ & $2(8 \%)$ & 0.257 \\
\hline Azithromycin & - & $1(4 \%)$ & - \\
\hline Clindamycin & - & $1(4 \%)$ & - \\
\hline Amoxicillin & $2(2 \%)$ & - & - \\
\hline Duration of Antibiotic (days) & $3.92 \pm 2.75(1.00-7.00)$ & $15.25 \pm 11.12(3.00-30.00)$ & 0.003 \\
\hline Menstrual Cycles & & & 0.061 \\
\hline Regular & $90(90 \%)$ & $19(76 \%)$ & 0.0001 \\
\hline Irregular & $10(10 \%)$ & $6(24 \%)$ & 0.371 \\
\hline \multicolumn{4}{|l|}{ Obstetric History } \\
\hline Gravidity & $3.77 \pm 2.63(1.00-14.00)$ & $3.08 \pm 2.55(0.00-9.00)$ & 0.240 \\
\hline Parity & $2.35 \pm 2.26(0.00-13.00)$ & $2.48 \pm 1.98(0.00-7.00)$ & 0.793 \\
\hline Abortion & $0.47 \pm 0.90(0.00-5.00)$ & $0.68 \pm 1.03(0.00-4.00)$ & 0.314 \\
\hline Premature Rupture of Membranes & $2(2 \%)$ & $2(8 \%)$ & 0.127 \\
\hline Weeks of Gestation (weeks) & $33.67 \pm 3.88(25.00-40.00)$ & - & - \\
\hline Mode of Previous Deliveries & & & 0.295 \\
\hline Normal Vaginal Delivery & $58(58 \%)$ & $16(64 \%)$ & 0.0001 \\
\hline Cesarean Section & $17(17 \%)$ & $1(4 \%)$ & 0.0001 \\
\hline Normal Vaginal Delivery and Cesarean & $9(9 \%)$ & $4(16 \%)$ & \\
\hline Section & $16(16 \%)$ & $4(16 \%)$ & \\
\hline Primigravida & & & \\
\hline Previous Neonates & & & 0.057 \\
\hline Full Term & $95(95 \%)$ & $21(84 \%)$ & 0.0001 \\
\hline Preterm & $5(5 \%)$ & $4(16 \%)$ & 0.527 \\
\hline Neonatal Deaths & $9(9 \%)$ & - & 0.119 \\
\hline Previous Neonatal Diseases & & & 0.073 \\
\hline Septicemia & - & $1(4 \%)$ & - \\
\hline Low Birth Weight & $1(1 \%)$ & $1(4 \%)$ & 1.000 \\
\hline Escherichia coli Isolation & & & 0.576 \\
\hline Positive & $21(21 \%)$ & $4(16 \%)$ & 0.001 \\
\hline Negative & $79(79 \%)$ & $21(84 \%)$ & 0.0001 \\
\hline
\end{tabular}




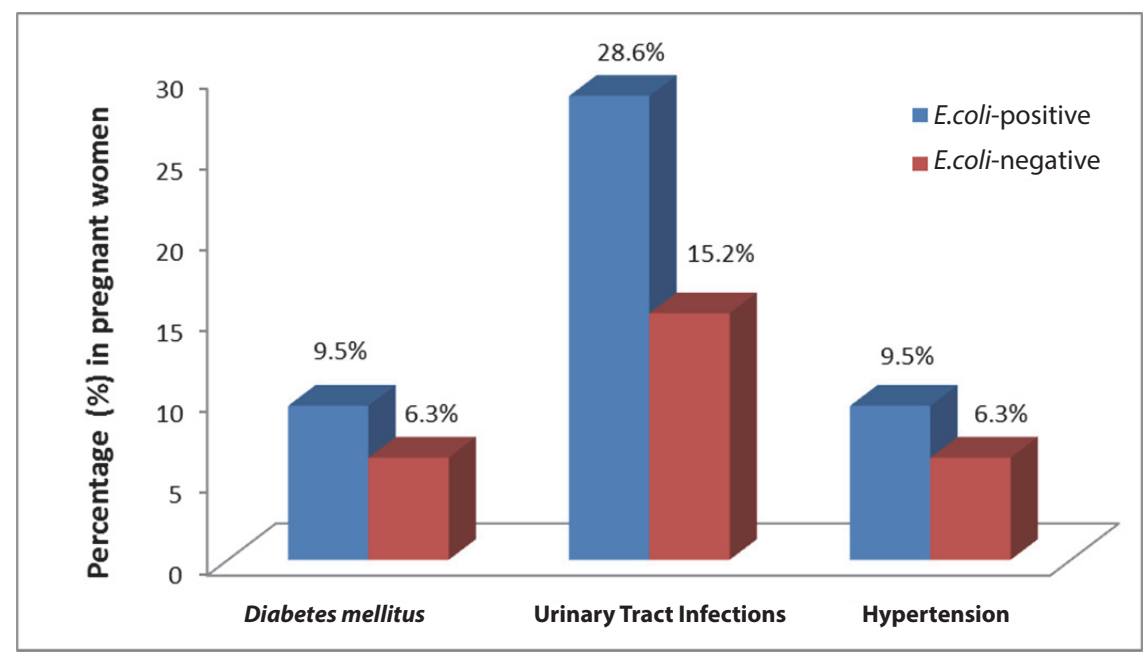

Figure 1. The distribution of diabetes mellitus, urinary tract infections and hypertension in Escherichia coli - positive and Escherichia coli - negative pregnant women. (E. coli: Escherichia coli).

Table 2. Co-morbidity of vaginal Escherichia coli - positive and negative in pregnant women).

\begin{tabular}{|l|c|c|c|}
\hline \multicolumn{1}{|c|}{ Parameters } & $\begin{array}{c}\text { E. coli-positive } \\
\text { (No.=21) }\end{array}$ & $\begin{array}{c}\text { E. coli-negative } \\
\text { (No.=79) }\end{array}$ & $\begin{array}{c}\text { Significance } \\
\text { (P. value) }\end{array}$ \\
\hline Co-morbidity: & \multicolumn{3}{|c|}{} \\
\hline Diabetes mellitus & $2(9.5 \%)$ & $5(6.3 \%)$ & 0.454 \\
\hline Urinary tract infections & $6(28.6 \%)$ & $12(15.2 \%)$ & 0.137 \\
\hline Smoking & - & $1(1.3 \%)$ & - \\
\hline Cancer & - & $1(1.3 \%)$ & - \\
\hline Previous Pre-eclampsia & $1(4.8 \%)$ & $1(1.3 \%)$ & 0.378 \\
\hline Hypertension & $2(9.5 \%)$ & $5(6.3 \%)$ & 0.454 \\
\hline Immunodeficiency & - & $2(2.5 \%)$ & - \\
\hline
\end{tabular}

E. coll: Escherichia coli

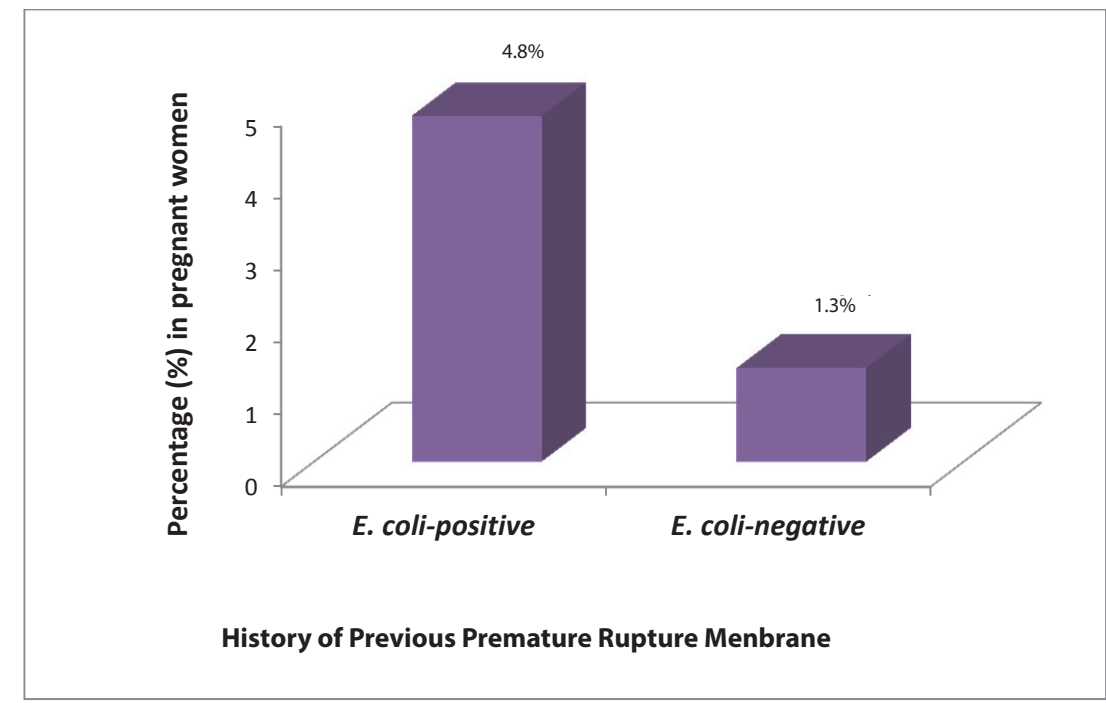

Figure 2. The distribution of history of previous premature rupture of membranes in vaginal Escherichia coli- positive and negative pregnant women. (E. coli: Escherichia coli). 
Table 3. Antimicrobial susceptibility pattern of Escherichia coli strains isolated from pregnant women.

\begin{tabular}{|l|c|c|c|c|}
\hline \multirow{2}{*}{ Antimicrobial Agent } & \multicolumn{4}{c|}{ Escherichia coli Isolates (No. = 21) } \\
\cline { 2 - 5 } & \multicolumn{2}{|c|}{ Susceptible (S) } & \multicolumn{2}{c|}{ Resistant (R) } \\
\hline & No. & (\%) & No. & (\%) \\
\hline Beta-lactam Drugs: & & & & \\
$\quad$ Ampicillin & 12 & 57.1 & 9 & 42.9 \\
Piperacillin & 12 & 57.1 & 9 & 42.9 \\
Meropenem & 21 & 100 & 0 & 0 \\
Cefuroxime & 21 & 100 & 0 & 0 \\
Cefotaxime & 21 & 100 & 0 & 0 \\
Cefepime & 21 & 100 & 0 & 0 \\
\hline Beta-lactam drugs/Beta-lactamase Inhibitors: & & & & \\
Amoxicillin/Clavulanate & 21 & 100 & 0 & 0 \\
Piperacillin/Tazobactam & 21 & 100 & 0 & 0 \\
\hline Aminoglycosides: & & & & \\
Amikacin & 21 & 100 & 0 & 0 \\
Gentamicin & 21 & 100 & 0 & 0 \\
\hline Quinolones: & & & & \\
$\quad$ Ciprofloxacin & 21 & 100 & 0 & 0 \\
\hline Nitrofurantoin & 21 & 100 & 0 & 0 \\
\hline Trimethoprim/Sulfamethoxazole & 13 & 61 & 8 & 38.1 \\
\hline
\end{tabular}

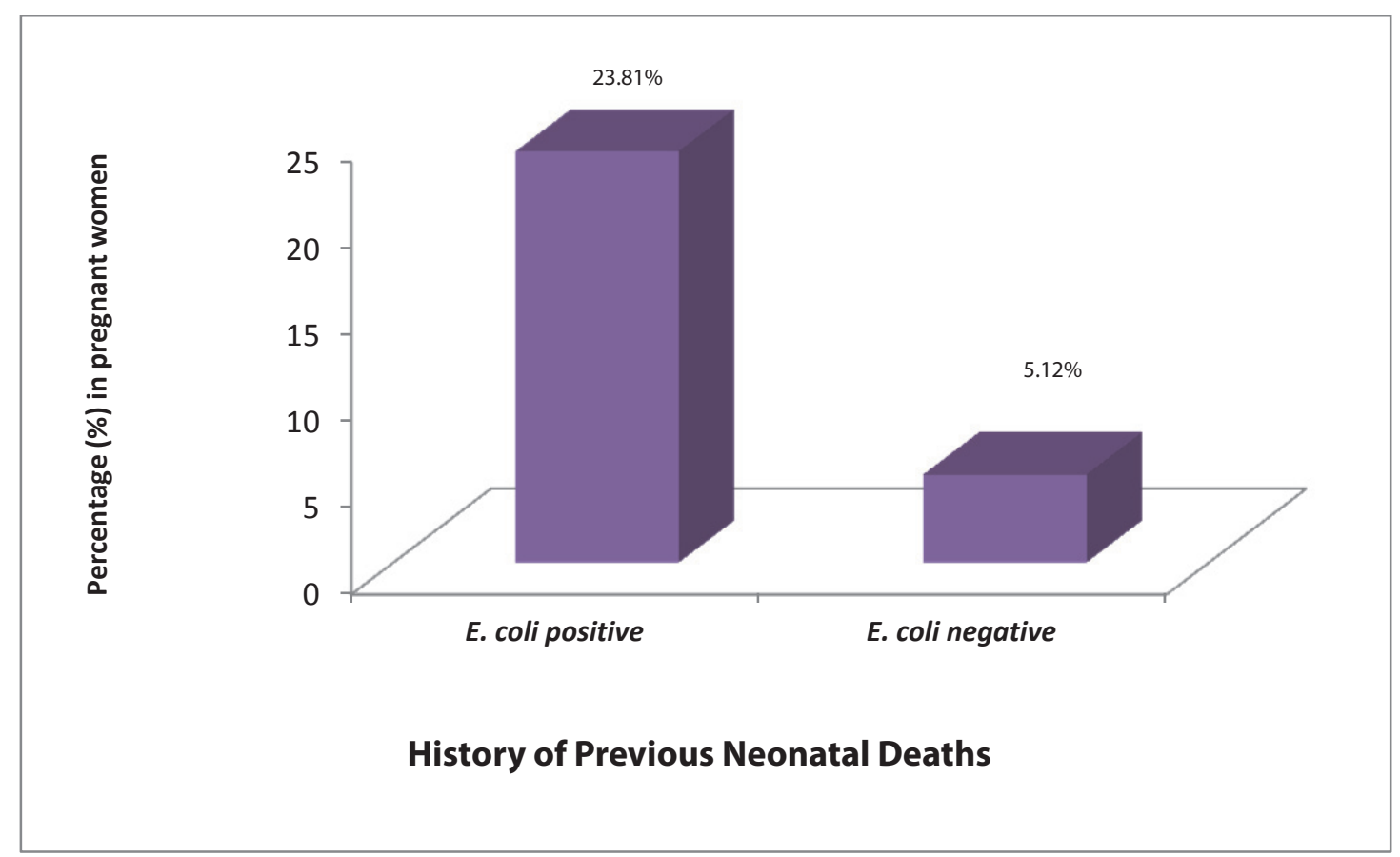

Figure 3. The distribution of history of previous neonatal deaths in vaginal Escherichia coli- positive and negative pregnant women. (E. coli: Escherichia coli). 
Table 4. The serotyping of Escherichia coli K1 in pregnant and non-pregnant women.

\begin{tabular}{|l|c|c|c|c|c|}
\hline \multicolumn{1}{|c|}{ Parameters } & \multicolumn{2}{|c|}{$\begin{array}{c}\text { Pregnant Women } \\
(\text { No. }=21)\end{array}$} & \multicolumn{2}{c|}{$\begin{array}{c}\text { Non-Pregnant Women } \\
\text { (No.=4) }\end{array}$} & $\begin{array}{c}\text { Significance } \\
\text { (P. value) }\end{array}$ \\
\hline & No. & $(\%)$ & No. & $(\%)$ & \\
\hline Escherichia coli K1- positive & 9 & $42.9 \%$ & 3 & $75 \%$ & 0.083 \\
\hline Escherichia coli K1- negative & 12 & $57.1 \%$ & 1 & $25 \%$ & $\mathbf{0 . 0 0 2}$ \\
\hline
\end{tabular}

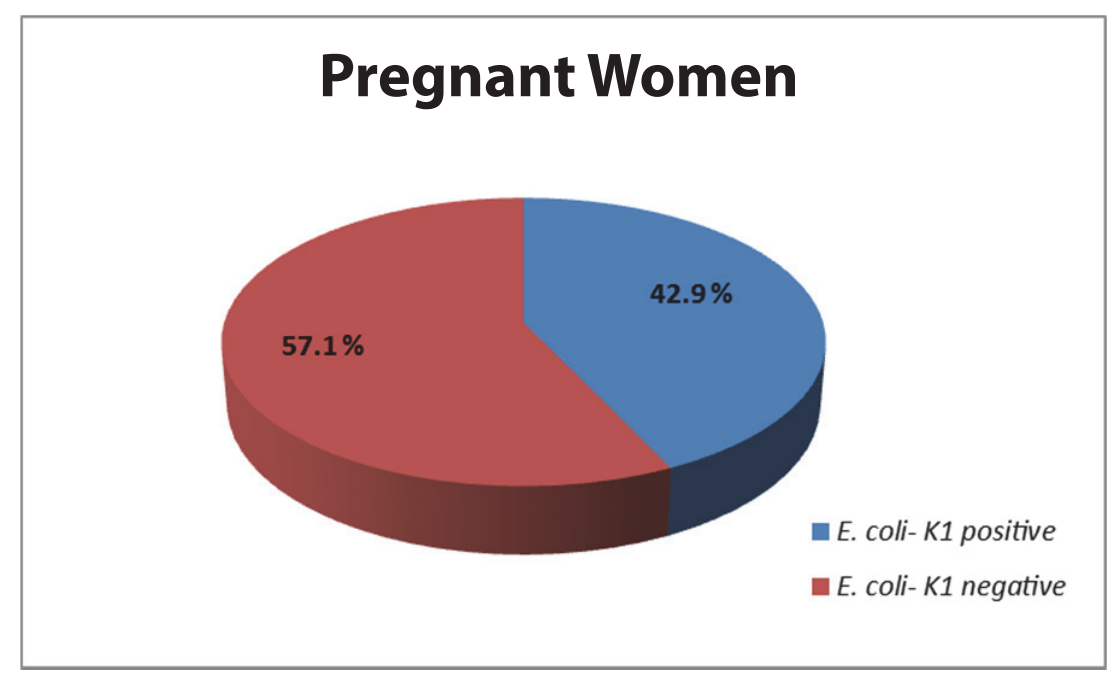

Figure 4. The distribution of vaginal Escherichia coli K1 and non-K1 Escherichia coli in pregnant women. (E. coli: Escherichia coli).

Escherichia coli is the most common cause of urinary tract infections (UTIs) among pregnant women, and UTIs are most frequent during pregnancy and can cause maternal-fetal morbidities including premature rupture of membranes, preterm birth, low birth weight, neonatal sepsis and perinatal death ${ }^{[31]}$. The present study revealed that the percentage of UTIs in E. coli-positive pregnant women (28.6\%) was more than in E. coli-negative pregnant women (15.2\%) with insignificant difference $(P=0.137)$.

Vaginal colonization by E. coli during pregnancy is strongly associated with PROM and is the most prevalent pathogen of neonatal sepsis in the neonates born after $\mathrm{PROM}^{[32,33]}$. In this study, the percentage of the history of previous premature rupture of membranes in E. coli-positive pregnant women (4.8\%) was higher than in E. coli-negative pregnant women (1.3\%) without significant difference $(P=0.378)$.

Vaginal colonization by $E$. coli is a common causative agent for life-threatening neonatal infections and it was detected in $21 \%$ of fetuses that have died during the third trimester of pregnancy. Thus, E. coli infections have been identified as the most common risk factor of death in neonates ${ }^{[34]}$. In this study, the prevalence of history of previous neonatal deaths in E. coli-positive pregnant women (23.8\%) was higher than in E. coli-negative pregnant women (5.1\%) with significant difference $(P=0.019)$; this could explain the relationship between vaginal $E$. coli colonization and neonatal deaths.

In this study, antimicrobial susceptibility tests were done by "VITEK 2" system where they showed that all the E. coli isolates (100\%) were susceptible to "meropenem, cefuroxime, cefotaxime, cefepime, amoxicillin/clavulanate, piperacillin/tazobactam, amikacin, gentamicin, ciprofloxacin and nitrofurantoin". Meanwhile, $42.9 \%$ of $E$. coli isolates were resistant to "ampicillin and piperacillin" and $38.1 \%$ were resistant to "trimethoprim \sulfamethoxazole". Some investigators reported same result as: Akerele et al., ${ }^{[25]}$ who found that all E. coli isolates (100\%) were sensitive to ciprofloxacin; Barcaite et al., ${ }^{[22]}$ in Lithuania found that all E. coli isolates (100\%) were susceptible to" cefuroxime, 
cefotaxime, amikacin and ciprofloxacin". In agreement with this result, Al-Mayahie ${ }^{[20]}$ in Iraq recorded that all E. coli isolates (100\%) were susceptible to meropenem and $31.5 \%$ of them were resistant to trimethoprim/ sulfamethoxazole. On the other hand, Al-Mayahie ${ }^{[20]}$ also reported different results that all $E$. coli isolates (100\%) were resistant to "amoxicillin/clavulanate and cefotaxime" and $36.8 \%, 31.5 \%$ of the isolates were resistant to "gentamicin and ciprofloxacin" respectively. In partial agreement with the present results, Barcaite et al., ${ }^{[22]}$ in Lithuania found that all of the $E$. coli isolates (100\%) were susceptible to "cefuroxime, cefotaxime, amikacin, and ciprofloxacin"; while they observed resistance to "ampicillin (25.9\%), piperacillin (16.6\%), ampicillin/sulbactam (7.8\%), gentamicin (2.6\%) and piperacillin/tazobactam (1.0\%)". The present findings were in the same ranges as that reported by Zai et al., ${ }^{[3]}$ in Pakistan who found that $77.7 \%$ of the isolates were susceptible to "gentamicin and $14.8 \%$ were susceptible to ampicillin". Some experts consider ciprofloxacin contraindicated during pregnancy especially during the first trimester ${ }^{[36]}$.

Escherichia coli strains that possess $\mathrm{K} 1$ capsular polysaccharide antigen can cause $40 \%$ of neonatal sepsis and $80 \%$ of neonatal meningitis ${ }^{[37]}$. The virulence of E. coli $\mathrm{K} 1$ strains is referred to the ability of the K1 capsular polysaccharide to repel phagocytic cells, inactivate complement system, resist antibodyindependent serum, cross the blood-brain barrier (BBB) and invade the brain microvascular endothelial cells ${ }^{[37]}$. In this study, vaginal E. coli K1strains isolated from pregnant women was $42.9 \%$. Also, a similar result by Obata-Yasuoka et al., ${ }^{[3]}$ in Japan who found that $E$. coli $\mathrm{K} 1$ in pregnant women was $40 \%$. However, a lower result was detected in a study done by Kaczmarek et al. ${ }^{\left[{ }^{[3]}\right.}$ in Poland who found that $20.9 \%$ of pregnant women were $E$. coli K1-positive.

\section{Conclusion}

The prevalence of the vaginal colonization by $E$. coli among pregnant women during the third trimester at KAUH in Jeddah, Saudi Arabia was $21 \%$. Out of them, $28.6 \%$ had urinary tract infections during their current pregnancies. Risk factors such as a history of previous premature rupture of membranes and previous neonatal deaths in these pregnant women were found to be $4.8 \%$ and $23.8 \%$ respectively. The virulent $E$. coli $\mathrm{K} 1$ strains were demonstrated in $42.9 \%$ of E. coli- positive pregnant women. The percentage of vaginal $E$. coli resistance to trimethoprim/sulfamethoxazole, ampicillin and piperacillin ranged from $38.1 \%$ to $42.9 \%$.

\section{Recommendations}

1. All women with a history of risk factors (such as urinary tract infections, premature rupture of membranes, neonatal sepsis, neonatal meningitis, and neonatal deaths) during their previous pregnancies should be screened for vaginal $E$. coli colonization.

2. All pregnant women should be screened for asymptomatic UTIs to decrease the risk of preterm labor and other complications.

3. Intrapartum antimicrobial prophylaxis can be given to pregnant women with vaginal colonization by $E$. coli in some high-risk cases.

4. Further studies should be carried out to investigate the transmission of vaginal E. coli from the pregnant women to their neonates.

\section{Conflict of Interest}

The authors have no conflict of interest.

\section{Disclosure}

None of the authors received any type of commercial support either in forms of compensation or financial for this study. They have no financial interest in any of the products or devices, or drugs mentioned in this article.

\section{Ethical Approval}

Obtained.

\section{References}

[1] Korczak B, Frey J, Schrenzel J, Pluschke G, Pfister R, Ehricht R, Kuhnert P. Use of diagnostic microarrays for determination of virulence gene pattern of Escherichia coli K1, a major cause of neonatal meningitis. J Clin Microbiol 2005; 43(3): 1024-1031.

[2] Watt S, Lanotte P, Mereghetti L, Moulin-Schouleur M, Picard B, Quentin R. Escherichia coli strains from pregnant women and neonates: intraspecies genetic distribution and prevalence of virulence factors. J Clin Microbiol 2003; 41(5): 1929-1935. 
[3] Obata-Yasuoka M, Ba-Thein W, Tsukamoto T, Yoshikawa H, Hayashi H. Vaginal Escherichia coli share common virulence factors profiles, serotypes and phylogeny with other extraintestinal E. coli. Microbiology 2002; 148(Pt 9): 27452752.

[4] Mohammad M, Mahdy ZA, Omar J, Maan N, Jamil MA. Laboratory aspects of asymptomatic bacteriuria in pregnancy. Southeast Asian J Trop Med Public Health 2002; 33(3): 575-580.

[5] Cadieux PA, Burton JP, Devillard E, Reid G. Lactobacillus byproducts inhibit the growth and virulence of uropathogenic Escherichia coli. J Physiol Pharmacol 2009; 60 Suppl 6: 1318.

[6] Villar HE, Aubert V, Baserni MN, Jugo M. Maternal carriage of extended-spectrum beta-lactamase-producing Escherichia coli isolates in Argentina. J Chemother 2013; 25(6): 324327.

[7] Bergström S. Infection-related morbidities in the mother, fetus, and neonate. J Nutr 2003; 133(5 Suppl 2): 1656S-1660S.

[8] Basu S, Ingale SY, Potdar VR, Patil B, Aundhakar CD. The study of the pattern of maternal vaginal flora in labour and its association with neonatal sepsis. IJRTSAT 2014; 10(1): 10-19.

[9] Tasson A, Speer C. Microbial pathogens causative of neonatal sepsis in Arabic countries. J Matern Fetal Neonatal Med 2001; 24(8): 990-994.

[10] Bassuni W, Abbag F, Asindi A, Al Barki A, Al Binali AM. Neonatal death in the Asir Region of Saudi Arabia: experience in a referral neonatal intensive care unit. Ann Saudi Med 1997; 17(5): 522-526.

[11] Zaria LT, Raufu IA, Mohammed HS. Isolation and antibiotic sensitivity of Escherichia coli from pregnant and nonpregnant women attending the University of Maiduguri Teaching Hospital (UMTH), Maiduguri, Nigeria. Int J Biomedical Health Sci 2010; 6(3): 159-164.

[12] Guiral E, Bosch J, Vila J, Soto SM. Prevalence of Escherichia coli among samples collected from the genital tract in pregnant and non-pregnant women: relationship with virulence. FEMS Microbiol Lett 2011; 314(2): 170-173.

[13] Mumtaz S, Ahmad M, Aftab I, Akhtar N, ul Hassan M, Hamid A. Aerobic vaginal pathogens and their sensitivity pattern. J Ayub Med Coll Abbottabad 2008; 20(1): 113-117.

[14] Soto S, Bosch J, Jimenez de Anta M, Vila J. Comparative study of virulence traits of Escherichia coli clinical isolates causing early and late neonatal sepsis. J Clin Microbiol 2008; 46(3): 1123-1125.

[15] American Academy of Pediatrics, Infectious Diseases. Escherichia coli diarrhea. In: Red Book: Report of the Committee on Infectious Diseases. Pickering LK, Baker CJ, Overturf GD, Prober CG, eds., 2008. 291-296.

[16] Devi U, Barman N, Barua P, MalikV, Das JK, Baruah P, Mahanta J. Vaginal carriage of antibiotic resistant Escherichia coliby pregnant women: a concern for the neonate. Clin Microbial 2014; 3(4): 153

[17] Collee JG, Miles RS, Watt B. Tests of identification of bacteria In: Mackie and MacCartney's Practical Medical Microbiology. Collee JG, Fraser AG, Marmion BP Simmons A. eds. 14 ${ }^{\text {th }}$ ed. New York: Churchill Livingstone, 2006. 131-149.

[18] Cheesbrough M. District Laboratory Practice in Tropical Countries Part 2. $2^{\text {nd }}$ edn. New York: Cambridge Uni P, 2006. 434.

[19] Krohn MA, Thwin SS, Rabe LK, Brown Z, Hillier SL. Vaginal colonization by Escherichia coli as a risk factor for very low birth weight delivery and other perinatal complications. J Infect Dis 1997; 175(3): 606-610.

[20] Al-Mayahie SM. Vaginal colonization by papG allele II+ Escherichia coli isolates from pregnant and nonpregnant women as predisposing factor to pyelonephritis. Infect Dis Obstet Gynecol 2013; 2013: 860402.

[21] August F. The microbial pattern associated with preterm rupture of membranes as seen at Muhimbili National Hospital. [Master's Thesis]. [Tanzania]: Muhimbili University of Health and Allied Science, 2009. 57.

[22] Barcaite E, Bartusevicius A, Tameliene R, Maleckiene L, Vitkauskiene A, Nadisauskiene R. Group B streptococcus and Escherichia coli colonization in pregnant women and neonates in Lithuania. Int J Gynecology Obstet 2012; 117: 69-73.

[23] Al-Inany M, Hanafy A, Tourky H, El-Kholy A. Effect of maternal colonization on early onset neonatal infection. Kasr Al Aini J Obstet Gynecol 2011; 2(3): 81-84.

[24] Hamedi A, Akhlaghi F, Seyedi S, Kharazmi A. Evaluation of group b streptococci colonization rate in pregnant women and their newborn. Acta Med Iran 2012; 50(12): 805-808.

[25] Akerele J, Abhulimen P, Okonofua F. Prevalence of asymptomatic genital infection among pregnant women in Benin City, Nigeria. Afr J Reprod Health 2002; 6(3): 9397.

[26] Agbakoba NR, Adetosoye Al, Adewole IF, Chukwuma CM. Isolation of vaginal pathogens along with genital mycoplasmas from asymptomatic gynecology and Antenatal Clinic attendees. Am-Euras J Sci Res 2008; 3(2): 195-198.

[27] Ghartey JP, Carpenter C, Gialanella P, Rising C, McAndrew TC, Mhatre M, Tugetman J, Einstein MH, Chazotte C, Herold BC. Association of bactericidal activity of genital tract secretions with Escherichia coli colonization in pregnancy. Am J Obstet Gynecol 2012: 207(4): 297.e1-8.

[28] Budisan C, Ilie C. The influence of maternal vaginal aerobic flora on newborn early infections. Jurnalul Pediatrului; XII 2009; 12(45-46): 33-35.

[29] Wong TB. Bacteriological study of high vaginal swabs in pregnant women in Evangel Hospital. Hong Kong Practitioner 1991; 13(9): 1673-1677. 
[30] Hassanzadeh P, Motamedifar M, Gharaghani MN. Carriage rate of Group B streptococci in pregnant women in three teaching hospitals in Shiraz, Iran. Med Princ Pract 2011; 20(3): 277-282.

[31] Vasconcelos-Pereira E, Figueiró-Filho E, OliveiraV, Fernandes A, Moura Fé C, Coelho L, Breda I. Urinary tract infections in high risk pregnant women. Rev Patol Trop 2013; 42(1): 2129.

[32] Karat C, Madhivanan P, Krupp K, Poornima S, Jayanthi NV, Suguna JS, Mathai E. The clinical and microbiological correlates of premature rupture of membranes. Indian J Med Microbiol 2006; 24(4): 283-285.

[33] Asindi AA, Archibong El, Mannan NB. Mother-infant colonization and neonatal sepsis in prelabor rupture of membranes. Saudi Med J 2002; 23(10): 1270-1274.

[34] Iregbu K, Zubair KO, Modibbo IF, Aigbe I, Sonibare SA, Ayoola OM. Neonatal infections caused by Escherichia coliat the National Hospital, Abuja: a three-year retrospective study. Afr J Clin Experimental Microbiol 2013; 14(2): 95-100.

[35] Zai S, Majeed S, Khatoon, J. Microflora in pregnancy. J Pak Med Assoc 1996; 36(4): 79-81.

[36] Meyer J, Rodvold K. Safety and toxicity of antimicrobials during pregnancy. Infect Med 1995; 12(11): 600-602, 606, 618.

[37] Kaczmarek A, Budzynska A, Gospodarek E. Prevalence of genes encoding virulence factors among Escherichia coliwith K1 antigen and non-K1 E. coli strains. J Med Microbiol 2012;61: 1360-1365. 


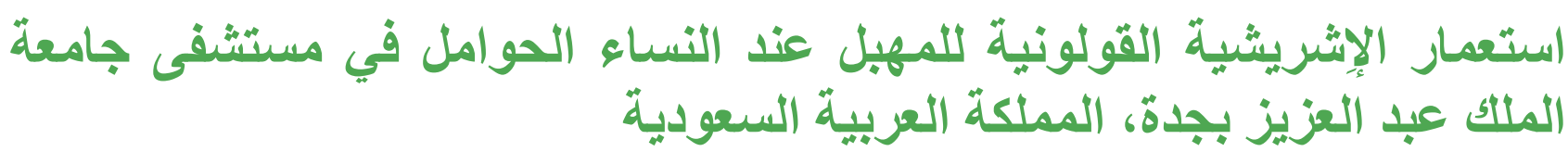

تغريد ياسر جمال'، وحسن البنا يونس"، وحسان صلاح عبدالجبارّ، وآصف أحمد جمعان فطاني؛، وأمل

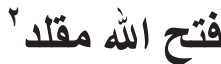

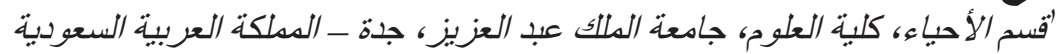

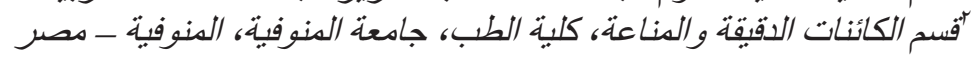

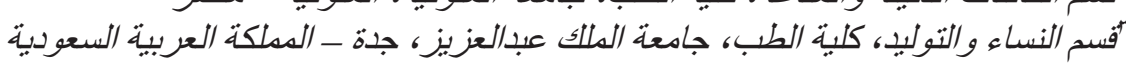

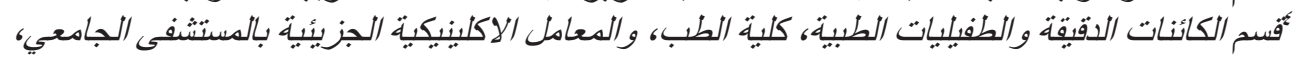

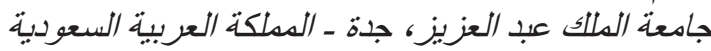

المستخلص. الإلتهابات الإشريشية القولونِية لدى الأمهات الحو امل و المو البد تمثل مشكلة لأطباء الأطفال و النساء و التوليد

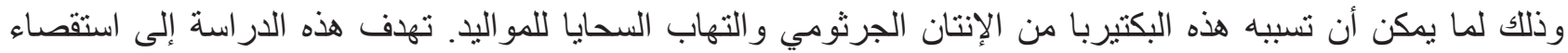

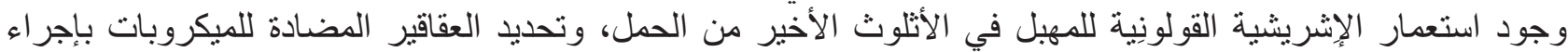

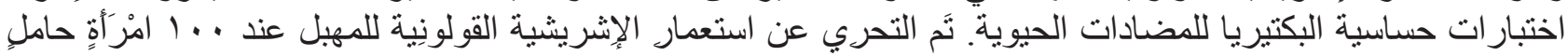

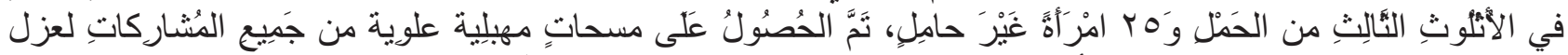

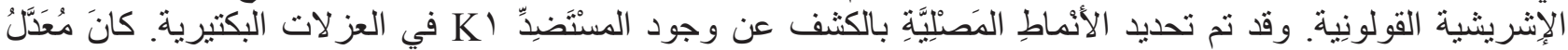

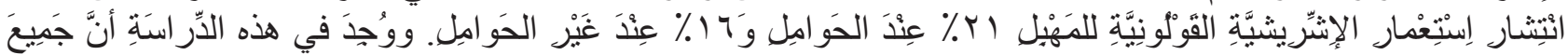

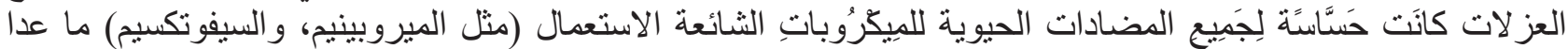

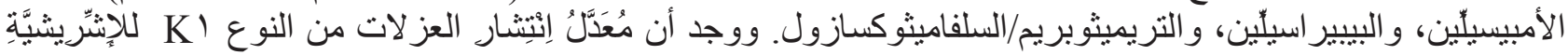

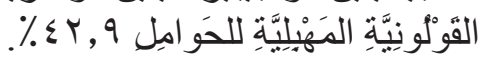

